females, can only convey the disease during the adult stage of their growth, a second series of experiments was undertaken. Dogs Nos. $5,6,7$, and 8 were selected, and kept under such circumstances that natural infection was an impossibility; for some time previous to infesting them with ticks their temperatures were carefully registered and their blood frequently examined.

Dogs Nos. 5 and 7 were infested with larval ticks, the progeny of infected females. The temperatures were taken regularly, and no rise was noticed; films of their blood were taken at frequent intervals, and no parasites could be seen. These two dogs are alive and well at time of writing.

Dogs Nos. 6 and 8 (a puppy and a full-grown dog respectively) were infested with ticks in the adult stage, the progeny of infected females, on 23 rd September. On the 4 th October the temperature of No. 8 was noticed to be above normal. Films from the blood were at once examined, and the causal parasite of malignant jaundice found to be present in the red corpuscles. On 5 th October the temperature of $\operatorname{dog}$ No. 6 showed a rise, and microscopical examination of the blood revealed the presence of the typical parasite.

That artificially-hatched adult ticks, the progeny of infected females, can produce this discase in healthy animals, I think must be admitted.

Age does not appear to give any protection from this disease, as in previous experiments I have been able to produce it by subcutaneous and intravenous inoculation in dogs of all ages, and with the utmost certainty.

In conclusion, it may be added that large quantities of dog's blood, containing the parasites in large numbers, have been injected intraperitoneally into guinea-pigs, pigeons, etc., without producing death, or even any lasting constitutional disturbance. This experiment was undertaken to ascertain if the parasite of malignant jaundice in the dog produced the caustic and irritant effects said to follow an intraperitoneal injection of Texas-fever blood, as stated by M. Lignière in his report on that disease in Argentina.

\title{
THE VETERINARY INSPECTION OF IMPORTED AMERICAN HORSES,
}

By Percy T. Howard, F.R.C.V.S., London.

IN this age of veterinary medical associations, periodicals, new works, etc., it is a difficult task to find a subject of a comparatively unhackneyed character. The busy practitioner has, owing to the need for preparation, little time or opportunity for the performance of experimental or research work, on which to base a scientific communication. Original views on well-thrashed-out points demand for their production an ability almost akin to genius. However, the material utilised in this paper is original, at least with regard to its source.

The inspection has been conducted in the combined interests of the shipowners and the underwriters of the horse insurancc, with a view to taking any steps, or submitting of any recommendations, that 
would conduce to the well-being of the horses while on board ship and for a short period after their debarkation, and thus reduce the mortality and sickness to a minimum.

The method of procedure is to make a tour of the ship on arrival, and note the more serious cases; after which a more detailed inspection is made of each horse when walking on to the quay from the ship's gangway, healthy horses being allowed to pass on, while sick ones are set aside for diagnosis to be made at leisure.

The notes and observations that follow are the outcome of an experience extending over a period of four years, during which time over 45,000 horses have been inspected by the writer at the time of debarkation, about $1000^{\circ}$ cases treated, and about 500 post-mortem examinations conducted on horses dying shortly after arrival in this country.

Conditions of the voyage and effects on horses:-The weather is undoubtedly an important factor. Otherwise healthy horses very rarely arrive with "filled" legs after a rough passage, the movement of the ship causing the horses to move, and circulation being thus assisted; the opposite is observed after a calm trip.

The condition of the atmosphere on the deck where the horses are carried is obviously a most important consideration. Not only have impurities resulting from respiration to be got rid of, but also gases, such as ammonia, etc., arising from the excreta, which are not removed until the ship arrives in port. Ventilating shafts (passing from the horse deck and opening on the non-covered-in part of the ship) and port-holes are provided with this intent, and serve the purpose well while the ship is in motion. In the event of the vessel coming to anchor through fog or any other cause, the ventilation becomes very defective unless large electric fans have been provided, which is very seldom the case. The atmosphere then becomes heated and malodorous; its effect on the animals is speedily made manifest by refusal of food, suffusion of the eyelids, and drooping heads; and those that have previously shown any tendency to "blow" will develop "pneumonia," or a kindred affection, from which they will speedily succumb unless relief is provided.

The state in which a cargo of horses lands is greatly dependent upon :-

(a). The carefulness with which infectious cases have been weeded out by the veterinary inspectors at the time of shipment in America ; and

(b). Whether the animals were in a "seasoned" or "green" condition at that time.

It is an undoubted fact that there is much less mortality amongst the former than the latter, although at first sight one would imagine that horses at hard work on a highly nitrogenous diet, such as thoroughbreds and harness horses, would suffer more from a ten days' idleness than "green" bus or van horses. It might be urged that this is explained by the difference in breed, but against that explanation is the statement that seasoned bus horses have landed in South Africa in very much better condition than raw remounts.

Casual examination of a comparatively healthy consignment made at the end of the voyage would most likely fail to discover any sign of the recent journey. A closer inspection would reveal an absence 
of "tone," or latent vitality, which is manifested in a variety of ways. Among these may be mentioned:-

(I). Rapidly shown fatigue on exertion.

(2). Small weak pulse (very persistent).

(3). Liability to rupture of internal organs, etc., if animals are subjected to sudden or violent exertion.

(4). The frequent occurrence of complete luxation of the patella.

Ruptured stomach has been most frequently seen, and next in order ruptured diaphragm, ruptured spleen, ruptured right auricle of heart, and ruptured posterior aorta.

Not one case of ruptured intestine is recorded with the foregoing, but a case possibly predisposed to by the conditions under review was intussusception of the small intestine.

The possibility of post-mortem accidents has always been considered in deciding as to the cause of death in these cases.

Mares in foal, especially towards the ninth month of gestation, frequently (sometimes three in a single trip) bear premature foals, which are usually dead. Fully developed live foals are sometimes born on the ship, but they seldom survive; at least one died from omphalo-thrombophlebitis.

A bnormally high temperature ( 2 or 3 degrees F.) occurs in many otherwise apparently healthy horses at the time of arrival; and on the following day, that is, after they have been landed about 24 hours, it has returned to normal. The explanation of this may be that it is caused by bacteria that require the assistance of the insanitary conditions prevailing in order to maintain their foothold in the animal body. The high temperature probably furnishes the chief cause of the premature labour above-mentioned.

It is here proposed to allude more particularly to some of the diseases and injuries incidental to this traffic, not so much with the idea of describing each one in detail, but rather of emphasising features that have arrested attention.

Diseases.-As will be surmised from the foregoing remarks relating to the atmosphere breathed by horses on ships, diseases such as pneumonia, influenza (and its complications), angina, pleurisy, pericarditis, and purpura hæmorrhagica, are by far the most frequent, especially pneumonia. Strangles, of course, may, and often does, exist with any of the preceding.

A disease which does not put in quite so regular an appearance as the above-named is an eye disease, which is probably specific ophthalmia; when noticed it is usual to find several cases on the same ship. Abdominal affections, with the exception of gastritis, enteritis, and fatty degeneration of the liver, are rare. Only two cases of volvulus are recorded in my notes on this subject. This apparently bears out the view that it is brought about by work, or the conditions of work.

Hrmoglobinuria is seldom seen in these horses while at sea, or during the first and second week after landing; such, however, unfortunately, is not the case when they are put to work.

Laminitis appears to be regarded by some as quite a common disease amongst horses at sea, but such has not been my experience. Occasional cases (not more than $I$ in IO0O) certainly occur, and usually with a fatal termination. 
Gangrenous stomatitis is sometimes seen; the sides and ventral aspect of the tongue become denuded of mucous membrane in patches up to 2 in. in size. The condition renders treatment difficult, as nourishment cannot be taken. The character of these cases is not infectious. Very possibly the complaint is not primary, but rather a sympton of purpura hæmorrhagica, the attack being of a non-typical character in other respects, which is not at all uncommon.

A few slight cases have been noticed where the inside of the upper and lower lips exhibited papules and vesicles-a condition sometimes regarded as variola equina. The cases were isolated, and no additicnal ones occurred; which was a different result to what was once noticed in an English stable, when by the time the first case was found several others were also affected, and it was thought that the groom in charge had received the virus in his arm, where a vesicular eruption resulted.

A vesicular eruption, which, after the epithelium is shed, leaves a circular patch about the size of a threepenny piece, not at all uncommonly affects the skin around the lips and nostrils. From the time that they are first observed until they disappear probably not more than a week elapses. They do not give rise to any inconvenience to the horse, but cases are seen where they are present on the pigmented integument at the floor of the nostril. My reason for thus rather fully dealing with what, on the face of it, appears to be an insignificant complaint, is because the uninitiated might jump to the conclusion that it was glanders. Beyond the occasional situation in the neighbourhood of the nostril, there is no similarity whatever between the two diseases, but, to make assurance doubly sure, one or two cases have been malleined, with negative results.

Injuries.-The injuries met with are not numerous, unless the ship rolls badly during the heavy weather, and the horses break loose on account of the fittings giving way, as, if I remember rightly, happened on the transport s.s. Rapialan soon after leaving Liverpool for South Africa. The best livestock-carrying ships will and do bring horses through the roughest weather without the slightest injury.

When the dimensions (beam) of a ship do not allow the stalls to possess sufficient length, the horses' tails, owing to the motion of the ship, become rubbed against the end of the stall. The friction first removes the hair, and, if it continues, may cause a raw wound. The tail may become paralysed.

An idea is in existence that mange is a common complaint amongst imported American horses, but such has not been my experience, though it is quite possible that the above rubbed condition of the tail has given rise to the suspicion. Inflammatory exudation is produced by the rubbing, and forms a crust or scab which might very easily be mistaken for the crust present in an attack of psoroptic mange, of which the root of the tail is a common seat.

Gathered nail is a not uncommon injury. The accident occurs at the time of embarkation, and, if not noticed then, is very probably unnoticed until the animal is landed. Inspection will reveal a discharge of pus from the coronet, and on probing the hoof is found to be under-run, possibly everywhere, and ready to drop off. All degrees of this are seen.

These foot cases, even when severe, do well under treatment as 
soon as the animal commences to recover from the effects of the voyage. "This is possibly to be attributed to the fact that the animal, being confined to a limited space, is unable to move, and thus add to the damage already present. The carelessness with which carpenters drop their nails about when building the stalls explains this accident, but this will soon be a thing of the past, as new stalls which are permanent fittings of the ship are now being adopted, and these avoid the use of nails entirely.

An important aspect of the subject can now be dealt with, viz., the relationship between the equine health of this country and the importation of American horses.

Are American horses conveying any kinds of infectious disease not previously existing in this country? Or are they adding to the prevalence of those that are practically enzootic, and thus causing loss to the horse-owning community? Further, if such a condition of affairs exist, what is the remedy?

The answer to the first of these questions at the present time would probably be in the negative. An allusion to the introduction of "pinkeye" in the past is contained in an editorial in the Veterinary Record, 6th July I90I. It says: "The now well-known term of 'pink-eye' is American, and was introduced into Britain with an outbreak of a special form of influenza about the end of the seventies." Another paragraph in the same article says: "The horses imported across the Atlantic introduced two forms of ringworm which have caused endless trouble to dealers and job masters."

Cases of ringworm have been very rare amongst the horses in this inspection. Consideration of the fact that the horses are collected from over a large continent will make it apparent that the introduction of new types of disease must always rank as a possible contingency, and be provided against accordingly.

Parasitic Diseases. - Those parasitic diseases common to both imported and native horses may roughly be divided for the purpose of consideration into $(a)$ those of bacterial, and $(b)$ those of animal nature.

Several bacterial diseases have already been referred to, and most of them, with perhaps the exception of purpura hæmorrhagica, are infectious in nature, and are classed under the heading on that account, even although in individual cases the exact bacterium is still at large and unlabelled.

One can scarcely imagine any conditions more favourable to the spread of infectious disease than those which of necessity prevail on the average vessel.

As already mentioned, there is the unfavourable atmosphere. In many cases it is impossible to move a sick horse for isolation purposes. Horses are on either side of a sick horse, and others are facing within a distance of 3 feet. Most of these complaints are characterised by nasal discharge; consequently every time the animal coughs or attempts to clear the nostrils a fine spray of infection is played upon the animals in the immediate vicinity.

A point of interest perhaps not directly bearing on the point under treatment is the confirmation, by my own personal observation, of a statement made in the Veterinary Record some time ago, viz., that the croupous laryngitis associated with a clear straw-coloured discharge is 
infectious to human beings. The attack lasts a few days, and is more uncomfortable than serious.

The variation in infective power and in severity of attack noticed in these diseases, especially in pneumonia and influenza, causes one to speculate as to whether each complaint has its specific organisin or whether their name is legion.

A commonly observed occurrence may be given as an illustration. A ship arrives with a cargo of horses, of which possibly four are suffering from acute pneumonia; after leaving the ship they improve and ultimately recover. The next time that the same ship arrives it will be found that there are just about the same number of cases of pneumonia, but a great difference is observed as to the termination of the attacks; probably the lungs become gangrenous, and the cases all terminate fatally.

It may be that this is merely an example of that variation in infectivity and malignancy which is seen from time to time in so many other diseases-influenza of human beings, for example. English horses when infected from those under consideration usually take the various complaints in a much more serious degree; dealers in both British and American horses are aware of this circumstance, and take measures accordingly. It seems possible that a native horse may serve as a suitable soil for increasing the virulence of the disease received from an American horse, in a similar way to that observed when a new cow is introduced into a herd recovering from an outbreak of abortion.

Glanders. - If this contagious disease were common amongst imported American horses, it would either be necessary for the traffic to cease, or else it would be necessary to enforce strict quarantine regulations on arrival in this country (probably accompanied by the mallein test). The extra expense thus entailed would naturally raise the price to the purchasers, possibly beyond their capacity to buy; but this consideration could have very little weight if the equine health in this country were threatened.

Fortunately for American horse-breeders, etc, it is most exceptional for a glandered horse to be shipped to this country. The number of recorded cases of glanders in imported American horses is stated to be six (Veterinary Record, 6th July I90I). Some of these cases were traced to the breaking up of a large stud of working horses in an American town.

The majority of horses that cross the water are about five years old and have never been in town stables, which no doubt explains their comparative freedom from glanders. My assertion that they are so is based on the fact that among the 500 post-mortem examinations before mentioned, I have not found more than one pair of lungs that one might suspect of glanders, although the tubercles are always searched for.

Whilst glanders remains as prevalent in London as at the present time, the infinitesimal amount amongst the "Yankees" can be disregarded. The placing of restrictions on them would savour too much of "straining at the gnat and swallowing the camel," but a time will and must come when glanders will be stamped out of this country, and the meshes of the net will then have to be made so small that even an occasional case of glanders will be unable to enter the country. 
The only way of doing that would be to mallein every horse after it has been allowed to settle down at a quarantine stable in the port.

The animal parasites infesting the alimentary tract of imported American horses do not include any varieties that are not observed in this country.

The gastrophilus is very constantly present on the cuticular portion of the mucous membrane of the stomach, and very often at the pyloric end of the duodenum as well; their number is often large.

The sclerostoma armatum and tetracanthum are comparatively common. Post-mortem examination where pneumonia has been the cause of death often reveals an accompanying enteritis due to the above parasites. Probably the debility caused by them rendered the animal more easy of conquest by the bacteria than would otherwise have been the case.

Such worms as the ascaris megalocephala and the curved oxyuris are not nearly so frequently seen as in British reared animals.

The filaria papillosa is more common in American horses; the peritoneal cavity is the seat. The parasite is not very interesting from a practical standpoint, as it is never sufficiently numerous to give rise to symptoms.

The measures necessary for the prevention of the spread of the before-mentioned infectious diseases should consist of :-

(I). Strict veterinary inspection of all horses when landed, in order that all cases of sickness may be isolated and retained at stables in the docks for treatment until recovery or death occurs. The healthy animals might proceed to their destinations.

(2). A more rigorous veterinary inspection at the time of embarkation, in order that only perfectly healthy animals may be shipped.

(3). Examinations of mangers and fittings by veterinary inspectors, to insure that thorough cleaning and disinfection have been carried out.

(4). Ventilation on the vessels, in addition to the usual provision, to be regulated by electric fans in all parts of the ship where necessary.

(5). Railway boxes and trucks, both here and in America, to be officially inspected to insure thorough cleanliness and disinfection.

Some of the above measures are now in force, but there is still something to be done, and there is a prospect that when that has been accomplished the percentage of deaths, although now low, may vanish completely, and thus add one more laurel to the crown of the veterinary art. 